\title{
Searches and clicks in Peninsular Spanish
}

\author{
Derrin Pinto and Donny Vigil \\ University of St. Thomas
}

\begin{abstract}
The current study analyzes the use of click sounds in Peninsular Spanish with a focus on those that occur when speakers are searching for what to say and signaling a particular stance. The data corpus consists of interviews with 18 speakers from Spain who produce a total of 281 clicks. We consider clicks to be a non-lexical discourse marker that conveys information to the listener regarding how an utterance should be interpreted. By applying a discourse-pragmatic approach from both quantitative and qualitative perspectives, we examine contextual and co-textual factors that co-occur with the click and contribute to a multimodal display consisting of pauses, fillers, repetitions, prolongations, gestures and object of search. The quantitative results indicate some statistically significant differences with regard to how clicks interact with the linguistic and extralinguistic environments. Qualitatively, we show evidence supporting the idea that clicks are part of a larger multimodal communicative activity.
\end{abstract}

Keywords: clicks, discourse markers, fillers, gestures, searches

\section{Introduction}

The use of clicks in Spanish is a topic that has not been investigated in depth. Most linguists and non-linguists alike are probably familiar with the existence of click sounds occurring in African languages since their percussive-like quality makes them somewhat unique. Texts on general linguistics and phonetics often discuss these phonemic clicks, frequently classified as ingressive stops or affricates, in the context of languages such as Zulu, Nama and Xhosa (Ladefoged 1982; Ladefoged 2005; Ladefoged and Maddieson 1996; Johnson 2003; O'Grady, et al. 1996; Reetz and Jongman 2009). It is understandable that most people do not associate click sounds with languages like Spanish and English, given that their usage is para-linguistic or non-phonemic in these and other Western languages.

In a previous study (Pinto and Vigil, 2018), we analyzed a data corpus of clicks produced by speakers from Spain with a focus on five different functions 
and several elements present in the contiguous pre- and post-click environment, including pauses, fillers and prolonged syllables. In this follow-up study, given previous reports (González Temer 2014 and Ogden 2013) suggesting that gestures are also an important element to consider when analyzing clicks, we look into a group of the most relevant gestures: gaze/thinking face, head movement, brow movement, lip movement, blinking, and shoulder movement. In addition, we incorporate a qualitative analysis in order to delve into the nuances involved in click usage. This wider focus acknowledges the fact that clicks are part of a larger multimodal phenomenon, especially since these sounds themselves are void of semantic content.

\section{Background}

Given the paucity of research on clicks in Spanish, studies in English have revealed a range of different functions and characteristics that inform our present study. Beginning with the phonetic properties discussed for English clicks, most of these sounds are described as having an alveolar (Ogden 2013; Ward 2006; Wright 2011a) or dental (Ogden 2013; Wright 2011a) place of articulation, with the tip or blade of the tongue serving as the active articulator. Other clicks reported in previous research are bilabial (Wright 2005, 2011a, 2011b), and these are often audibly weaker than their alveolar counterparts. Among the functions that have been identified for clicks are those related to sequencing, including signaling incipient speakership (Ogden 2013) or marking new sequences of talk (Wright 2005, 2007, 2011a, b), word searches (Ogden 2013; Ward 2006; Wright 2005, 2011a) and different types of stance-taking positions by the speaker such as dissatisfaction, disapproval or other affective displays (Benor 2004; Ogden 2013; Reber 2012; Ward 2006). Regarding their placement, researchers have observed clicks occurring both in the turn-initial position (Ogden 2013; Ward 2006; Wright 2005) and in the middle of a turn (Ogden 2013; Ward 2006; Wright 2005). Ogden (2013) also observed a small number of turn-final clicks, but he attributes these to speakers starting a new utterance that is then abandoned. While not all of the aforementioned researchers analyze video footage, such as Wright $(2005,2007,2011$, b) who only considers telephone conversations, Ogden (2013) found that gestures contributed essential cues to the interpretation of clicks. For example, Ogden describes one particular case in which a daughter responds to her mother's preceding comment by clicking while simultaneously directing her gaze away, two interrelated actions that together express resistance to the mother's previous statement about the daughter not being able to buy a dress. 
For clicks in Spanish, González Temer (2014) appears to be the first interaction-based study that goes beyond unsystematic observations of the phenomenon (e.g. Mott 2011; Zilio 1986). Based on a relatively small corpus $(n=38)$, González Temer's study on Chilean Spanish sets out to determine whether or not clicks in Spanish fulfill similar functions to those reported for English. Comparable to the English studies cited above, González Temer identified both alveolar and bilabial clicks in her data, along with two lateral clicks, and she reported their occurrence in the three aforementioned positions (initial, mid and final). With regard to function, González Temer also found stance-taking $(n=17)$, incipient speakership $(n=11)$ and word searches $(n=10)$. An important observation made by the researcher is the presence of certain fillers such as $\mathrm{eh}$ 'uh' and $\mathrm{ehm}$ 'um' with word searches in particular, either immediately before or after the click. This phenomenon involving the co-occurrence of fillers and clicks was also described by Wright (2005, 2011a) for English. Lastly, similar to Ogden (2013), González Temer discussed the role that accompanying gestures play (e.g. blinks, head movement and lip protrusion), especially with regard to stance-taking clicks.

Fillers, clicks and certain gestures are part of what Clark (2004) and Clark and Fox Tree (2002) refer to as collateral signals, the markers that speakers use to manage their ongoing performance. The fact that previous researchers studying clicks have alluded to the co-occurrence of filler words and gestures highlights the importance of these collateral signals working together as part of a multimodal means of expression, including the use of verbal and nonverbal modes (Chandler and Munday 2011). Regarding fillers in particular, not only do clicks often co-occur with these discourse particles but they potentially carry out similar functions. For example, James (1973) summarizes the different functions that $u$ carries out in English, which include indicating that the speaker is trying to think of what to say, is trying to remember something, is reluctant to say something or is uncertain about the right words or the hearer's reactions. Concerning the possible benefits to the addressee, there is some evidence that fillers like $u h$ and $u m$ can lead to positive effects in the comprehension process, such as helping the listeners facilitate recall (Fraundorf and Watson 2011) or orient them to new information (Barr and Seyfeddinipurr 2010). This latter function is comparable to what Wright (2011a) observed for those clicks in English that demarcate new and disjunctive sequences of talk.

One major difference between fillers and clicks is that clicks are instantaneous and cannot be extended to buy time while one is hesitating (Ogden 2013). Additionally, clicks differ from at least some filler words in that they do not carry any inherent semantic meaning, making their contribution highly dependent on the context and co-text. Given these characteristics of clicks, we consider them a type of non-lexical discourse marker (DM). DMs have been studied in 
a variety of languages and from an array of theoretical perspectives (e.g. Ariel 1998; Brinton 1996; Fraser and Malamud-Makowski 1996; Fraser 1999; Jucker and Ziv 1998; Montes 1999; Schiffrin 1987; Torres 2002; Torres and Potowski 2008; Travis 2005; Roggia 2012; Schwenter 1996; Tagliamonte 2005). Travis $(2005,48)$ describes DMs as words or expressions that convey information about either "how an upcoming or prior utterance is to be understood in the context of the surrounding discourse" or with regard to some aspect of the speaker's attitude. A search click, for example, by signaling the speaker's uncertainty about how to express something, also implies that the subsequent utterance should be interpreted tentatively. In this sense, search clicks intersect with a particular type of interjection called evincives, "a linguistic item that indicates that at the moment at which it is said the speaker is engaged in, or has just then been engaged in, thinking" (Schourup 1982,18). Another essential feature of DMs that applies to clicks is that they can be multifunctional, thus a single token may imply more than one function or meaning (Brinton 1996; Schiffrin 1987; Travis 2005). For instance, to consider a DM in Spanish, Schwenter (1996) offers examples of how a single token of $o$ sea 'that is' provides a connective function, indicating how the relationship between two utterances should be interpreted, as well as an epistemic commentary of the speaker's subjective belief or experience. Lastly, similar to DMs such as eh 'uh' in Spanish (Roggia 2012), clicks can introduce different discourse segments, including turns and sentences, but they also appear between syntactic constituents (i.e. between a determiner and a noun or a verb and a direct object). Nevertheless, not all DMs lend themselves to this same type of flexibility regarding placement, as Martín Zorraquino and Lázaro (1999) discuss for Spanish DMs.

This study approaches clicks from a discourse-pragmatic perspective in the sense that click function is intimately linked to other co-textual and contextual phenomena such as pauses, fillers and co-occurring gestures. In addition to the immediate linguistic environment around the click, a discourse focus implies a wider macro-level consideration beyond the utterance level, allowing us to take into account the role that topic can have on clicks. Analyzing clicks as DMs provides a framework in which we can investigate how a non-lexical sound with no inherent semantic core interacts with micro- and macro-level factors to convey a range of meanings. By the same token, both linguistic and extralinguistic elements are intimately connected, and as Poyatos $(1984,309)$ points out, gestures are communicating activities that serve to "complement the semantic contents of verbal language." Interestingly, although not the focus of his study, Poyatos mentions clicks along with words, gestures and silence as resources that potentially contribute to conveying meaning: "a given behavior (a word, a click, a shoulder shrug or even a silence) can support, emphasize or contradict the basic 
message" (Poyatos 1984,314). The ways in which different types of gestures and facial expressions play a part in communicating essential information has been reported by researchers working in fields including kinesics, communication, linguistics and psychology (e.g. Corballis 2002; Ekman 2003; Ekman and Wallace 2003; Hostetter 2011; Huttunen et al. 2013; Poyatos 1985).

\section{Method}

\subsection{Participants and data}

The clicks in this study are part of a larger corpus of clicks, produced by 20 native speakers of Spanish from Spain, discussed in Pinto and Vigil (2018). For the present analysis, we excluded two of the original speakers due to concerns about their gestures not being discernable in the video, giving us a total of 18 speakers. Although we do not take into consideration the variables of gender, age and profession, there are nine females and nine males ranging from 30 to 62 years of age whose professions include politics, journalism, and the arts. These participants appeared in interviews that were publicly available online. In order to ensure a robust corpus of clicks, we selected these interviews by applying the minimum baseline that a speaker must produce at least five clicks in the first five minutes of the interview. This selection process is not meant to yield findings that are necessarily representative of the general Spanish population, especially with regard to frequency of click usage. The total amount of actual speaking time of the interviewees for the 18 videos was 411 minutes (191 for females, 220 for males). While we used the video footage for our analysis, we also converted the videos to mp3 audio files, allowing us to analyze different aspects of the interviewee's speech using Praat (Boersma and Weenink 2007).

In Pinto and Vigil (2018) and Wright (2011b), clicks in Spanish and English respectively can be produced with both alveolar/dental and bilabial points of articulation. To represent the clicks in the examples taken from our data corpus, we opt for the symbol () which does not specify place of articulation.

\subsection{Classification of clicks}

The 281 clicks in this study comprise the two categories that occurred with the highest frequency in our previous study, 'Search' $(n=173)$ and 'Search-Stance' $(n=108)$. For that study, the coding process that we implemented entailed two evaluators assigning functions individually. At the completion of the coding process, we carried out a Cohen's Kappa inter-rater reliability test which yielded 
a rating of Kappa $=.84$, considered to be very good agreement (Altman 1991). The subset of clicks selected for the present study occur at the turn-medial position, meaning some other linguistic element (words or fillers) occurred immediately before the click. While the larger corpus used in Pinto and Vigil (2018) did contain turn-initial clicks, this particular category of 'opening clicks' was not included in this present study. 'Search', frequently referred to as a word search, has been reported as a common function for English clicks (González Temer 2014; Ogden 2013; Wright 2005, 2011a). Given that searches can involve momentary delays as the speaker looks for the best way to articulate his or her thoughts, we prefer to call this category 'Search' rather than 'Word Search'. To illustrate an example of the search function, (1) shows an excerpt taken from an interview with a Spanish journalist who specializes in international soccer. In this segment he talks about a time earlier in his career when he wanted to exchange videos of soccer games with people in different countries. With this in mind, he placed an advertisement in a sports magazine to see if others were interested in trading videos. The speaker's utterance here contains two searches, the first for recibi 'I received' without a click, occurring after a pause of 0.73 seconds, and the second for contestación 'answer', appearing after a pause of 0.97 seconds, a click and the slightly elongated filler $e h$ 'uh'. For the second search the speaker also exhibits a thinking face.

(1) ...puse un anuncio pues un anuncio que un chaval español quería intercambiar partidos entonces (0.73) recibi (0.97) () (0.00) eh: contestación de mucha gente de afuera que quería lo mismo

'...I placed an advertisement uh an advertisement that a Spanish guy wanted to exchange games so (0.73) I received (0.97) $\odot$ (0.00) uh: an answer from a lot of people abroad that wanted the same thing'

The second category, 'Search-Stance', is a hybrid of two functions. Similar to previous research on discourse markers (Brinton 1996; Schiffrin 1987), more than one function can be attributed to a particular linguistic device. In conjunction with the search, the stance aspect of this category refers to a variety of stance-taking or affective displays (González Temer 2014; Ogden 2013; Wright 2011a; Reber 2012). This description is used for cases in which "the speaker appears to be searching for the right way to say something while also displaying an emotional reaction to the topic that may be potentially offensive, controversial, disappointing, exciting, etc." (Pinto and Vigil, 2018, 450) In some cases, the stance displayed seems to be more metadiscursive in nature, an attitudinal commentary on the speaker's word choice or lack of ability to find the right way to say something, rather than a reaction to the actual topic itself.

In Example (2), the interviewer asks a professor about how her background from a working-class family shaped her as a person. She discusses a time from her 
childhood when her family did their best to help out others who were in need. She also remembers being exposed to other children with lice and getting lice herself, one of many memories that contributed to an awareness of her working-class background. These experiences are framed in a positive light in the sense that, thanks to her humble upbringing, she learned to empathize with the needs of others.

(2) ...y luego yo decía es que yo cojo piojos porque me me llevas a niñas y niños con piojos, claro que sí a algún sitio tienen que ir estos niños, no? Es que eso es muy mucho mi infancia y me me bueno no es que me condicione es que yo creo que me ha determinado absolutamente (0.65) () (0.55) por suerte, en el sentido de que bueno yo creo que tienes como la capacidad, no? de detectar muy rápido dónde están las necesidades

'....and then I said that I get lice because you take me me to girls and boys with lice, of course these kids need to go somewhere, right? It's just that this is really my childhood and well it's not that it conditioned me me it's that I believe it absolutely shaped me (0.65) ( ) (0.55) luckily, in the sense that well I believe you have the capacity, right, to quickly detect where the needs are'

In addition to co-occurring with a search for por suerte 'luckily', the click is a manifestation of the speaker's desire to effectively express the ironic juxtaposition of unpleasant experiences and their beneficial impact, especially in hindsight from an adult perspective. The stance here also seems partially metadiscursive, a passing moment of dissatisfaction as she grapples with the best way to articulate this contradictory notion of feeling fortunate to have faced discomfort in order to learn an important lesson.

\subsection{Object of search, gestures and click environment}

Other studies on searches have used object of search as one of the important aspects to investigate (Wright 2005; Hayashi 2003; Brouwer 2003). The categories we code for are Noun, Adjective, Adverb, Verb and Means of Expression. Noun can be a single noun (ilustraciones 'illustrations'), or a noun phrase (el presidente Jefferson 'President Jefferson'). Adjective can be a single adjective (digitales 'digital', espectacular 'spectacular'), or an adjectival phrase (menos frío 'less cold'). In our data, Adverb refers to adverbial phrases (de esta forma 'this way', por suerte 'luckily'). Verb may include a verb (invadir 'to invade') or verb phrase (me ha cautivado 'has captivated me'). With this first series of categories, the speaker interrupts the flow of speech to engage in the cognitive process of accessing the mental lexicon. The idea here is akin to somebody searching and saying 'what is that word I'm trying to think of?' With the last category, Means of Expression, rather than a search for a particular lexical unit (noun, noun phrase, etc.), the speaker is thinking about 
how to best articulate his/her thought or idea. The search here could be conveyed with the question 'how can I say this?' or 'what do I want to say here?' The segments that occur with Means of Expression would largely be considered, in grammatical terms, a clause or a sentence. For example, an actor in our corpus paused and clicked while searching for, or thinking about how to express, the following statement: si miro hacia atrás he hecho más drama que comedia 'if I look back I have done more drama than comedy'. In some instances, the searched-for item is not necessarily the first to appear immediately after the click (e.g. when a filler word such as eh 'uh' occurs before a searched-for noun).

Previous research on searches and clicks has shown that certain types of body language play a role in revealing information about a speaker's mental state or attitudes (e.g., Goodwin 1983; Goodwin and Goodwin 1986; Eckman 1979; Ogden 2013; Argyle and Cook 1976; González Temer 2014). Based on some of these findings, we selected six categories of gestures to analyze. While these categories do not exhaust all the possible options, we determined that they are among the most observable in our corpus. The six categories are: gaze/thinking face, head movement, brow movement, lip movement, blinking, and shoulder movement.

The literature on word searches has highlighted the importance of gaze aversion and the commonly referred to "thinking face" (Argyle and Cook 1976; Goodwin 1983; Goodwin and Goodwin 1986; Hayashi 2003). When speakers engage in a word search, they often withdraw their gaze from the listener. According to Goodwin $(1983,130)$, when looking away, the "speaker adopts a gesture which is recognizable in our culture as a thinking face, a gesture which embodies the activity of trying to remember a word." In our study, since they occur hand in hand, we combine gaze aversion and thinking face into one category.

In two studies on clicks, Ogden (2013) in English and González Temer (2014) in Spanish, head movement is mentioned as a possible gesture that may accompany the click. In our analysis, we consider head movement to include moving the head forward, up and down or side to side. In cases in which head movement is a natural result of gaze aversion, we do not count it as a separate action. In addition to head movement, González Temer (2014) also observes lip protrusion as a gesture that can occur with stance clicks. Different types of lip movement are also prevalent in our data, not only as lip protrusion but also as lip pursing, lip licking and raising the corner of the lip. Regarding lip pursing, this gesture often coincides with the prolonged use of $\mathrm{mmm}$.

The last three gestures entail brow movement, shoulder movement, and blinking. According to Eckman (1979), brow movement is common with word searches. In these cases, "the brow actions may serve to signal the listener not to interrupt or take over the speaker turn." (Eckman 1979,186). While we did not see shoulder movement and blinking reported in other studies on searches or 
clicks, we observed in our initial analysis of the data that these could be important. For shoulders, we consider noticeable upward movement of the shoulders, which could be referred to as shrugging. Regarding the last category, blinking, we count either heavy and exaggerated blinking, or multiple blinking, as in a fluttering of the eyelids. Lastly, although hand movement is widespread in our corpus, given the fact that the hands are not visible in all of the videos for the duration of the interview, we opted not to code for this.

One question that surfaced during our analysis of gestures was how far from the click a given gesture would be considered relevant to the function of the click. Since all of the clicks in this study involved searches, we concluded that the window for coding gestures would correspond to the duration of the speaker's search process. In order to determine the duration of the search, we relied on linguistic and non-linguistic evidence, such as gaze aversion and the use of fillers or pauses that indicate that the flow of speech was being interrupted.

Existing research on clicks highlights the importance of co-occurring elements in the environment contiguous to the click such as fillers, prolonged words, pauses and repetitions (Wright 2005; Pinto and Vigil, 2018). These features, in conjunction with the click, may provide further evidence that the speakers are in the process of searching or monitoring their speech. For each click in our data, we determined whether the preceding element was a non-filler lexical item, a filler or a pause (a minimum length of 0.5 seconds). The same coding system was employed in the post-click environment. A separate category was utilized for repetitions across the click when the same word was repeated immediately before and after the click. Lastly, if the word or filler before and after the click was elongated over 0.5 seconds, we coded this separately.

\subsection{Research questions}

The quantitative research question that we set out to answer in our analysis is as follows:

1. What are the characteristics of the click functions of Search and Search-Stance and, applying the criteria described below, is there statistically significant evidence that they are distinct groups?

i. Object of search (Noun, Adjective, Adverb, Verb and Means of Expression)

ii. Gestures (gaze/thinking face, head movement, brow movement, lip movement, blinking, and shoulder movement)

iii. Contiguous environment (fillers, prolongation and pauses in both preand post-click position; repetitions across the click) 
The qualitative research questions that guide our analysis are as follows:

1. What do clicks contribute to a search episode?

2. How do Search and Search-Stance differ and how does multimodality play a role in conveying this difference?

\section{Results}

\subsection{Quantitative results}

The first research question concerns the characteristics of the click functions of Search and Search-Stance. Starting with the element being searched for, our goal is to determine whether or not there is statistically significant evidence that Search and Search-Stance are distinct groups. Although she does not provide quantitative findings, Wright (2005) observed that nouns were typically the most searched-for item in her English data set. Table 1 displays the frequencies and percentages of the object of search for both Search and Search-Stance. We ran two-proportion ztests for each of the five categories, with the null hypothesis being that there would be no difference $(\alpha<0.05)$. The results of the tests yielded statistically significant differences for Noun $(p=0.000)$ and Means of Expression $(p=0.001)$. From a total of 173 Search clicks, 44 were used for Noun, accounting for $25 \%$ of the searched for objects, whereas only 6 of the 108 Search-Stance clicks (or 5\%) were used for Noun. On the contrary, from the 108 Search-Stance clicks, 83 (or $77 \%$ ) were used for Means of Expression, versus only 102 out of 173 (or 59\%) of the Search clicks.

Table 1. Statistics for object of search: Z-test for two proportions

\begin{tabular}{lccl}
\hline Object of search & Search & Search-stance & $p$-value \\
\hline Noun & $44(25 \%)$ & $6(5 \%)$ & 0.000 \\
Means of Expression & $102(59 \%)$ & $83(77 \%)$ & 0.001 \\
Adjective & $7(4 \%)$ & $8(7 \%)$ & 0.252 \\
Verb & $17(10 \%)$ & $7(7 \%)$ & 0.307 \\
Adverb & $3(2 \%)$ & $4(4 \%)$ & 0.341 \\
Total & $\mathbf{1 7 3}$ & $\mathbf{1 0 8}$ & \\
\hline
\end{tabular}

With regard to gestures, we set out to discover if results from the z-tests provide evidence indicating that Search and Search-Stance are distinct groups $(\alpha<0.05)$. Table 2 contains total occurrences and percentages for the six categories that we analyzed. Head movement shows a statistically significant difference 
between Search and Search-Stance $(p=0.013)$. While head movement was more common with Search-Stance, accounting for $54 \%$ of these clicks, it occurred with only $39 \%$ of Search clicks. For the rest of the gestures, the findings are not statistically significant.

When taking into consideration both Search and Search-Stance, gaze and lips are the most frequently used gesture. As mentioned above, averting gaze has been widely reported in other studies on searches, and the phenomenon commonly involves two aspects, both gaze aversion and thinking face. Although a statistically significant difference for gaze is not observable between the two groups, usage is high for both Search (92\%) and Search-Stance (95\%). Lip movement was the second-most frequent gesture in our corpus, $77 \%$ for Search and $71 \%$ for SearchStance, a result that may be partially attributed to the high occurrence of lip protrusion coinciding with the common filler $\mathrm{mmm}$.

Table 2. Statistics for gestures: Z-test for two proportions

\begin{tabular}{lrrl}
\hline Gestures & \multicolumn{1}{l}{ Search } & Search-stance & $p$-value \\
\hline Head & $67 / 173(39 \%)$ & $58 / 108(54 \%)$ & 0.013 \\
Lips & $134 / 173(77 \%)$ & $77 / 108(71 \%)$ & 0.253 \\
Shoulders & $22 / 173(13 \%)$ & $19 / 108(18 \%)$ & 0.274 \\
Gaze & $160 / 173(92 \%)$ & $103 / 108(95 \%)$ & 0.311 \\
Brows & $62 / 173(36 \%)$ & $35 / 108(32 \%)$ & 0.554 \\
Blinks & $26 / 173(15 \%)$ & $17 / 108(16 \%)$ & 0.872 \\
Total & 471 & 309 & \\
\hline
\end{tabular}

For the last group, the elements found in the environment contiguous to the click, our objective is once again to determine whether or not the results from z-tests show evidence indicating that Search and Search-Stance are distinct groups $(\alpha<0.05)$. In Table 3 we include the nine categories that we identified as potentially relevant to click usage. The three categories that demonstrate statistical significance are the following: pre-lexical, repetitions, post-filler and post-prolongation (small sample size).

Starting with the position immediately before the click, pre-lexical items are more common than fillers or pauses with Search-Stance (47\%) than with Search (34\%). To illustrate the use of a lexical item preceding a click, in Example (3) below, the word cuando ('when') occurs before the click.

(3) ...iba a pasar al tercero cuando (0.18) () (0.50) me di cuenta... ‘...I was going into my third year when $(0.18) \odot$ (o.50) I realized... 
Repetitions across the click are more frequent with Search (35\%) than with SearchStance (20\%). In the segment in (4), one can see that the speaker repeats the verb son ('are') before and after the click:

(4) ...unas lógicamente son (0.00) () (0.25) son eh hamsas eh islámicas... '...some logically are (0.00) () (0.25) are uh Islamic uh hamsas...'

Post-fillers, fillers appearing directly after the click, are more common with Search (23\%) than with Search-Stance (7\%). In Example (5), the speaker utters pues ('well') after clicking and a short pause.

(5) ...eso implica una fase en la que (0.13) () (o.32) pues de alguna manera... '...this implies a phase in which (o.13) ๑ (o.32) well in some way...'

Lastly, the category of post-prolongation occurs more often with Search (14\%) than with Search-Stance (2\%). In Example (6), the speaker elongates the $y$ ('and') after the click.

(6) ...yo siempre venía de deportes eh colectivos (0.76) @ (o.02) y:: siempre me imaginaba jugando en equipo...

'...I always used to play uh team sports (0.76) () (0.02) and:: I always saw myself playing on a team...'

Table 3. Statistics for contiguous elements: Z-test for two proportions

\begin{tabular}{lccl}
\hline Contiguous & Search & Search-stance & $p$-value \\
\hline Pre-lexical & $59(34 \%)$ & $51(47 \%)$ & 0.029 \\
Pre-pause & $62(36 \%)$ & $30(28 \%)$ & 0.153 \\
Pre-filler & $56(32 \%)$ & $28(26 \%)$ & 0.243 \\
Pre-prolongation & $61(35 \%)$ & $36(33 \%)$ & 0.740 \\
\hline Repetition across click & $61(35 \%)$ & $22(20 \%)$ & 0.005 \\
\hline Post-filler & $40(23 \%)$ & $8(7 \%)$ & 0.000 \\
Post-prolongation & $24(14 \%)$ & $2(2 \%)$ & 0.000 \\
Post-lexical & $123(71 \%)$ & $87(80 \%)$ & 0.066 \\
Post-pause & $11(6 \%)$ & $11(10 \%)$ & 0.268 \\
Total & 497 & 275 & \\
\hline
\end{tabular}

To summarize, the quantitative results show the following: Search is more likely to entail trying to find the appropriate noun (Table 1), it is associated with a higher frequency of certain collateral signals (post-fillers, post-prolongations and repetitions across the click) (Table 3), and it is less commonly associated with head movement (Table 2). Search-Stance, on the other hand, shows a higher 
likelihood to involve searching for a means of expression rather than a noun or single word (Table 1), a more frequent use of head movement (Table 2) and prelexical items (Table 3), as well as a weaker association with post-fillers, post-prolongations and repetitions across the click (Table 3 ). We discuss these findings in more detail below in Section 5.

\subsection{Qualitative results}

The first question we want to address concerns what exactly the click contributes to a search episode. Since searches often occur without clicks, they have to be considered an optional resource that speakers can draw on to communicate additional information. Wright (2005), in her analysis of telephone conversations in English, suggested the possibility that the search click was used to indicate that the speaker is still searching for a word and that the recipient should not interrupt. The author emphasizes the fact that, since her data consist solely of telephone conversations, due to the absence of visual cues like thinking face, the click in these instances carries out an important turn-holding function. In Pinto and Vigil (2018), we point out that search clicks, and clicks in general, tend to come after a notable pause and shortly before the person resumes speaking. While the pre-click pause average was $0.41 \mathrm{~s}$ for Search, the post-click pause average was half as long, 0.19s (Pinto and Vigil, 2018). Given that search clicks generally appear further toward the end of the search process (see Example 1 above), it does not seem logical that they are primarily being used to signal holding the floor while the speaker is thinking. This evidence suggests that these search clicks actually indicate something else, such as uncertainty about whether or not the speaker has the right word(s) to express his or her thoughts, comparable to a type of modality marker. Similar to what Roggia $(2012,1789)$ points out for eh in Spanish, the click might signal that the upcoming segment of discourse is "something that has been given thought". Yet another explanation can be found in Ward (2006), in his study of clicks in English. Ward (2006) refers to the idea of clicks expressing dissatisfaction, whether it be about the topic or something related to the actual speaking process itself. In the case of a search, the speaker can be dissatisfied with his or her own performance (e.g. the inability to find the right words and the need to pause), which may explain why the click appears toward the end of a delay when the speaker detects processing trouble. This notion of dissatisfaction brings us to the next qualitative research question regarding how Search-Stance differs from Search and the role that multimodality plays.

To reiterate, Ward's aforementioned comment underscores the link between searching for what to say and the different possible attitudes that surface in conjunction with the search, such as feeling dissatisfied or frustrated about the 
interruption in the flow of speech, about the word selection or a combination of both. In our data, while searches displaying detectable attitudes such as dissatisfaction were coded Search-Stance, it might be possible to propose that all search clicks indicate some degree of speaker dissatisfaction with his or her performance, regardless of whether or not such an attitude is always perceivable to the listener (or evaluator, in our case). From this perspective, what distinguishes Search from Search-Stance is likely a matter of degree, depending largely on how many linguistic and non-linguistic signals come together to express the stance in question. Here is where multimodality comes into play in the sense that numerous linguistic and extralinguistic factors combine, including topic, lexical/semantic content, pauses, prolongation, fillers, repetition and gestures. In isolation, each factor might not convey the stance in question, but together they have a compounded effect. A particular attitude surrounding a click may only be evident when a certain threshold level is reached, when the co-occurring signals align in such a way that a stance is conveyed. Examples (7) and (8) described below illustrate how multimodality manifests itself with Search-Stance clicks.

In an interview with a politician from the region of Castilla-La Mancha (7), the interviewer asks about the political and environmental lessons learned from an experience involving a recent fire at a landfill with 15,000 tons of discarded tires. After opening with a popular saying about not procrastinating, he uses the filler $e h$ 'uh' which is slightly elongated, averts his gaze away from the interviewer, clicks, and then simultaneously furrows his brow while heavily blinking before pursing his lips and continuing to speak by saying es verdad que 'it's true that'. This segment of his utterance starts off with a combination of repetitions (que este que que este 'that this that that this'). It is the sum of interrelated elements here that express the Search-Stance. The linguistic/discursive factors include the sensitivity of the topic (i.e. a costly and politically controversial fire), the expression of an opinion, the click, the elongated filler $e h$ 'uh' and the use of repetition. The contributing extralinguistic aspects consist of gaze aversion, brow movement, exaggerated blinking and lip pursing.

(7) ...bueno pues que no dejes para mañana lo que puedes hacer hoy eh: (o.10) () (o.26) es verdad que este que que este es un problema complicado y que tiene muchas aristas y que hay que dejar trabajar primero a los profesionales para que todo para que todo esté:: controlado...

'...well don't put off for tomorrow what you can do today um: (o.10) ( $)(0.26)$ it's true that this that that this is a complicated problem and that it has a lot of layers and that one has to let the professionals work first so that everything is:: under control...' 
In another interview (Example 8), an actor is speaking about the breakup of an important relationship in his past. He suggests that the end of the relationship was one of the contributing factors that impelled him to go on to become a successful actor. In this segment, the speaker looks down and exhibits thinking face and then produces a false start ending with an elongated yo 'I' that trails off (en fin que bueno que yo::: 'anyway it's good that I:::'). He then begins another attempt with mira 'look', purses his lips as he utters a lengthy $\mathrm{mmm}$ that lasts 1.2 seconds while simultaneously shaking his head, and raises his brows as he exaggeratedly blinks his eyes. Lastly, the speaker flutters his eyelids between the two repeated tokens of que 'that'. Here again, we have a case of multimodal elements working together to express Search-Stance. In addition to the aforementioned characteristics, the topic concerns conflicting emotions about the failed relationship together with the serendipity regarding the end of the relationship and the impetus to move to Madrid and pursue an acting career. The gestures that play a part are gaze, brows, blinks and lips.

...en fin que bueno que yo::: mira mmm:::::: (o.19) () le agradezco profundamente que que me dejase porque gracias a esa ruptura ((aposiopesis)) - y aparte creo que ((interviewer interrupts)) '....anyway it's good that I::: look mmm:::::: (o.19) @ I am profoundly grateful to her that that she left me because thanks to that breakup ((aposiopesis)) - and besides I believe that ((interviewer interrupts))'

While we have discussed multimodality in the context of Search-Stance, the phenomenon is also relevant for Search. In Example (9), a representative of the wine industry for Castilla-La Mancha is speaking about budgetary details regarding the wine industry in the region. In this sample, the speaker clicks while apparently searching for establecido 'established'. The search process begins with gaze aversion right before el patronato 'the board', followed by the elongated use of $h a$ 'has', a short pause of 0.38 seconds, the click (co-occurring with head movement), the prolonged filler $\mathrm{mmm}$ as well as the repeated and lengthened use of $h a$ 'has'. There is also a heavy, fluttering blink that accompanies $\mathrm{mmm}$ and the ensuing $h a$ 'has'.

(9) ...y y los siguientes años es decir los tres últimos años el patronato ha:::: (o.38) () (o.12) mmm: ha: ha:: establecido cuota cero es decir no no aportar porque había suficiente dinero para eh desarrollar las acciones que se estaban presupuestando...

'and and the following years that is the last three years the board has:::: $(0.38)(\odot$ (o.12) $\mathrm{mmm}$ : has: has:: established a zero cuota that is to say not not investing because there was enough money to uh develop the shares that were being budgeted for' 
While some of the highlighted features in (9) are similar to those used for SearchStance, the affective involvement of the speaker and the overall emotional tone are noticeably weaker. The topic itself of the budget is more routine, at least in this particular segment, and the series of collateral signals (filler, click, prolongations, repetitions and gestures) merely appear to be manifestations of a processing lapse as the speaker searches for the right word(s).

\section{Discussion}

For the first quantitative research question addressing the object of search for Search and Search-Stance, the two statistically significant findings that are represented in Table 1 have a logical explanation when taking into account one of the fundamental differences between the two categories. To summarize, Search is more likely to be associated with Noun while Means of Expression is more expected with Search-Stance. The circumstances of Search can be different from those of Search-Stance in that Search is more likely to involve a single lexical item or unit, generally a noun or noun phrase, while Search-Stance tends to imply that the speaker is unsure about the best way to express his/her thoughts, which coincides with the category Means of Expression. One common cause for uncertainty with Search-Stance is when people are talking about a sensitive or controversial topic and are monitoring how they will articulate their idea. For example, in an interview (10) with an engineering professor after the nuclear disaster in Japan 2011, the interviewer asks the guest about the situation in Europe with other nations reconsidering their nuclear power programs. The interviewee responds by pointing out some of the dangers involved with nuclear energy:

...hay muchos otros aspectos de la energía nuclear que son negativos y que yo creo que tenemos que enfocar desde una perspectiva global. Em bueno lo que está pasando en Japón es muy grave (o.65) ๑ (o.09) y:: la energía nuclear tiene sus problemas...

'there are many other aspects of nuclear energy that are negative and that I believe we have to approach from a global perspective. Um well what is happening in Japan is very serious (o.65) ( (0.09) and:: nuclear energy has its problems...'

The click in this example signals both a search and an apparent awareness of the sensitive nature of the topic pertaining to the problems surrounding nuclear energy, as well as an effort by the speaker to hedge her opinion. It is also worth pointing out that, although la energía nuclear 'nuclear energy' is the first element to appear when the speaker resumes speaking (after an elongated $y$ 'and'), it seems 
obvious when listening to this segment of the interview that this noun phrase is not actually what the speaker is searching for. That is, not only is la energía nuclear 'nuclear energy' the primary topic of the interview and the interviewee's area of specialty, this noun phrase also appears in the preceding sentence. With this in mind, the search here is one that entails Means of Expression as the professor contemplates what to say or how to say it.

Another quantitative finding was that Search is associated with a higher frequency of certain collateral signals surrounding the click; namely, post-fillers, post-prolongations and repetitions across the click (Table 3). Taking into consideration the aforementioned tendency for Search clicks to occur more frequently with Noun, these findings might all be interrelated. Assuming that the speaker is trying to remember, or think of, a specific noun or noun phrase, the post-click uncertainty can manifest itself in an elongated filler (e.g. $\mathrm{mmm}$ or $\mathrm{eh}$ ) before the word is finally produced. To show an example of this, in (11) one of the interviewees is talking about promoting wines from Castilla-La Mancha. In this search segment, after clicking, and before producing the searched-for la promoción 'marketing, he utters an elongated $e h$ :

(11) Pero evidentemente la fundación tiene también muy presente y ((inaudible)) muy significativo (o.69) ( ( $(0.21)$ eh:: la promoción en la Unión Europea

'But evidently the foundation is very aware of and ((inaudible)) very important (o.69) () (o.21) uh:: marketing in the European Union’

Repetitions across the click are also common when the searched-for element is Noun. The repetitions can involve common words occurring before nouns, such as definite and indefinite articles or verbs. In one of the interviews with a comic artist, the interviewee talks about making the career transition from doing cartoons to comics. In this particular segment (12), he searches for la decisión 'the decision', and while doing so, he repeats tomé 'I made' before and after the click:

(12) Entonces tomé (o.12) @ (o.20) tomé la: la decisión en un momento dado de dejar todo eso

'So I made (0.12) () (0.20) I made the: the decision in a given moment to leave all of that'

Considering again Example (9) in Section 4.2, although the searched-for item is a past participle of a verb rather than a noun, this segment contains all three of these phenomena that are more likely to occur with Search: post-filler $(\mathrm{mmm})$, post-prolongation (of the filler $\mathrm{mmm}$ ) and repetition of ha 'has' across the click.

Regarding the quantitative results for gestures, head movement, as indicated in Table (2), was more common with Search-Stance clicks (54\%) than with Search clicks (39\%). Since Search-Stance implies a higher level of emotional involvement, 
having more instances of head movement is understandable. Given this statistically significant finding for head movement, one might expect similar results for other gestures as well. Ultimately, though, a frequency difference in gesture usage may not be able to be captured quantitatively, hence the importance of incorporating a qualitative perspective. Qualitatively, the gestures combine and interact with the elements surrounding the click in subtly different ways to convey Search or Search-Stance. Furthermore, it is important to keep in mind that some movements are more dynamic or exaggerated than others. For example, in line with the more personal nature of the topic concerning the end of a relationship, the body language accompanying the Search-Stance click in (8) is, as a whole, comparatively more expressive than that which appears with the Search click in the "budget” Example (9).

As we emphasized above in Section 4.2, all the nuances involved need to be studied from a holistic, multimodal perspective encompassing a range of issues, even beyond those that we considered here. The level of expressivity conveyed through a given click depends on a number of interrelated elements, including but not limited to the discourse topic, the speaker's feeling about the topic or about his or her performance, saliency of the click sound, prolonged syllables, the use of pauses, fillers, repetitions, swallowing, intonation, inbreaths, eye gaze, blinking and a combination of possible gestures such as head, shoulders, brows, hands and lips. All these features combined could be regarded as possible components of the larger phenomenon of a search event, within which the click is just one small piece. Similar to the cognitive and social aspects described by Clark and Fox Tree (2002) for fillers, namely, that they reflect the speaker is monitoring his/ her speech while also signaling that there is something (e.g. a delay or uncertainty) worth communicating to the hearer, the same applies to search clicks. In this sense, both fillers and clicks, according to Brennan and Williams (1995), can contribute to the goal of "coordinating individual mental states during communication" (397). The subtleties involved in communicating these mental states, especially regarding stance-taking clicks, is an area worthy of further examination. Given that the topic of click usage in Spanish has yet to be widely investigated, delving into the range of attitudes expressed is just one of the many avenues of research that remain to be explored.

\section{Conclusion}

In the current study, we sought to investigate the quantitative and qualitative differences between Search and Search-Stance clicks. For these two types of clicks, we quantified and analyzed the object of search, accompanying gestures and 
certain co-occurring collateral signals. The results indicated that Search clicks were more frequently used when searching for nouns, while Search-Stance clicks involved looking for a means of expression. Furthermore, Search-Stance clicks were more commonly associated with head movement than Search clicks, but less likely to occur with post-fillers, post-prolongations and repetition across the click.

Beyond these findings, there are questions that cannot be answered quantitatively, such as what a click contributes to a search event. More than anything else it appears to function as a type of hedge for what the speaker is about to say. We saw that, more often than not, the click does not come at the beginning of the delay in speaking, hence the evidence suggests that the Search click's main function is not to signal a search but to communicate something else to the listener (i.e. the speaker's feeling of uncertainty about what to say). In some cases, this uncertainty can also be simultaneously accompanied by a stronger sense of dissatisfaction or even frustration, and this is where Search-Stance clicks enter the picture. When these clicks are used, the overall level of affective display communicated through linguistic and paralinguistic channels is higher and more dynamic. Given these nuances involved in click usage, we underscore the importance of taking into consideration a multimodal approach when analyzing their function.

\section{Acknowledgements}

We would like to give thanks to Dr. Arkady Shemyakin for his recommendations regarding our statistical tests.

\section{References}

Altman, Douglas G. 1991. Practical Statistics for Medical Research. London: Chapman and Hall. Argyle, Michael, and Mark Cook. 1976. Gaze and Mutual Gaze. Cambridge: Cambridge University Press.

Ariel, Mira. 1998. “Discourse Markers and Form-function Correlations.” In Discourse Markers, ed. by Andreas Jucker, and Yael Ziv, 223-259. Amsterdam/Philadelphia: John Benjamins. https://doi.org/10.1075/pbns.57.12ari

Barr, Dale, and Mandana Seyfeddinipurr. 2010. "The Role of Fillers in Listener Attributions for Speaker Disfluency." Language and Cognitive Processes 25: 441-455. https://doi.org/10.1080/01690960903047122

Benor, Sarah. 2004. "Second Style Acquisition: The Linguistic Socialization of Newly Orthodox Jews." Doctoral Dissertation, Stanford University.

Boersma, Paul, and David Weenink. 2007. Praat: Doing Phonetics by Computer (Version 4.5.14). http://www.praat.org/ 
Brennan, Susan E., and Maurice Williams. 1995. “The Feeling of Another's Knowing: Prosody and Filled Pauses as Cues to Listeners about the Metacognitive States of Speakers." Journal of Memory and Language 34: 383-398. https://doi.org/10.1006/jmla.1995.1017

Brinton, Laurel J. 1996. Pragmatic Markers in English. Berlin/New York: Mouton de Gruyter. https://doi.org/10.1515/9783110907582

Brouwer, Catherine E. 2003. "Word Searches in NNS-NS Interaction: Opportunities for Language Learning?” Modern Language Journal 87: 534-545. https://doi.org/10.1111/1540-4781.00206

Chandler, Daniel, and Rod Munday. 2011. A Dictionary of Media and Communication. Oxford: Oxford University Press. https://doi.org/10.1093/acref/9780199568758.001.0001

Clark, Herbert H. 2004. “Pragmatics of Language Performance.” In Handbook of Pragmatics, ed. by Laurence R. Horn, and Gregory Ward, 365-382. Oxford: Blackwell.

Clark, Herbert H., and Jean E. Fox Tree. 2002. "Using Uh and Um in Spontaneous Dialog." Cognition 84: 73-111. https://doi.org/10.1016/Soo10-0277(02)00017-3

Corballis, Michael. 2002. From Hand to Mouth: The Origins of Language. Princeton: Princeton University Press.

Eckman, Paul. 1979. “About Brows: Emotional and Conversational Signals.” In Human Ethology: Claims and Limits of a New Discipline: Contributions to the Colloquium, ed. by Mario von Cranach, Klaus Foppa, Wolfgang Lepenies, and Detlev Ploog, 3-55. Cambridge: Cambridge University Press.

Ekman, Paul. 2003. Emotions Revealed. New York: Holt Paperbacks.

Ekman, Paul, and Wallace Friesen. 2003. Unmasking the Face. Cambridge, MA: Malor Books.

Fraser, Bruce. 1999. “What Are Discourse Markers?” Journal of Pragmatics 31: 931-952. https://doi.org/10.1016/So378-2166(98)00101-5

Fraser, Bruce, and Malamud-Makowski, M. 1996. "English and Spanish Contrastive Discourse Markers." Language Sciences 18: 863-881. https://doi.org/10.1016/S0388-0001(96)00052-6

Fraundorf, Scott, and Duane G. Watson. 2011. “The Disfluent Discourse: Effects of Filled Pauses on Recall." Journal of Memory and Language 65: 161-175. https://doi.org/10.1016/j.jml.2011.03.004

González Temer, Verónica. 2014. "Clicks in Chilean Spanish Conversation.” In Proceedings of the First Postgraduate and Academic Researchers in Linguistics at York, ed. by Theodora Lee, 74-99. www.york.ac.uk/language/ypl/PARLAY2013/PARLAY\%2oProceedings.pdf

Goodwin, Marjorie Harness. 1983. "Searching for a Word as an Interactive Activity." In Semiotics, ed. by John N. Deely, and Margot D. Lenhart, 129-138. New York: Plenum.

Goodwin, Marjorie Harness, and Charles Goodwin. 1986. "Gesture and Coparticipation in the Activity of Searching for a Word.” Semiotica 62: 51-75.

Hayashi, Makoto. 2003. "Language and the Body as Resources for Collaborative Action: A Study of Word Searches in Japanese Conversation." Research on Language and Social Interaction 36.2: 109-141. https://doi.org/10.1207/S15327973RLSl3602_2

Hostetter, Autumn. 2011. "When Do Gestures Communicate? A Meta-analysis." Psychological Bulletin 137(2): 297-315. https://doi.org/10.1037/aoo22128

Huttunen, Kerttu, Karen Pine, Angela Thurnham, and Catherine Khan. 2013. "The Changing Role of Gesture in Linguistic Development: A Developmental Trajectory and a Cross-cultural Comparison between British and Finnish Children." Journal of Psycholinguistic Research 42(1): 81-101. https://doi.org/10.1007/s10936-012-9205-7 
James, Deborah. 1973. “The Syntax and Semantics of Some English Interjections.” Doctoral Dissertation, University of Michigan.

Johnson, Keith. 2003. Acoustic and Auditory Phonetics. Malden, MA: Blackwell Publishing. Jucker, Andreas, and Yael Ziv. 1998. "Discourse Markers: Introduction." In Discourse Markers, ed. by Andreas Jucker, and Yael Ziv, 1-12. Amsterdam/Philadelphia: John Benjamins. https://doi.org/10.1075/pbns.57.03juc

Ladefoged, Peter. 1982. A Course in Phonetics. New York: Harcourt, Brace and Jovanovich. Ladefoged, Peter. 2005. Vowels and Consonants: An Introduction to the Sounds of Languages. Malden, MA: Blackwell Publishing.

Ladefoged, Peter, and Ian Maddieson. 1996. The Sounds of the World's Languages. Malden, MA: Blackwell Publishing.

Martín Zorraquino, María Antonia and José Portolés Lázaro. 1999. "Los marcadores del discurso." In Gramática Descriptiva de la Lengua Española, ed. by Ignacio Bosque, and Violeta Demonte, 4051-4213. Madrid: Espasa Calpe.

Montes, Rosa G. 1999. “The Development of Discourse Markers in Spanish: Interjections.” Journal of Pragmatics 31: 1289-319. https://doi.org/10.1016/S0378-2166(98)00106-4

Mott, Brian L. 2011. English Phonetics and Phonology for Spanish Speakers. Barcelona: Edicions Universitat Barcelona.

Ogden, Richard. 2013. "Clicks and Percussives in English Conversation." Journal of the International Phonetic Association 43: 299-320. https://doi.org/10.1017/So025100313000224

O'Grady, William, Michael Dobrovolsky, and Francis Katamba. 1996. Contemporary Linguistics. Harlow, England: Longman.

Pinto, Derrin, and Donny Vigil. 2018. "Clicks as discourse markers in Peninsular Spanish." Spanish in Context 15(3): 441-464. https://doi.org/10.1075/sic.00022.pin

Poyatos, Fernando. 1984. “The Multichannel Reality of Discourse: Language-paralanguage-kinesics and the Totality of Communicative Systems." Language Sciences 6: 307-337. https://doi.org/10.1016/So388-0001(84)80022-4

Poyatos, Fernando. 1985. “The Deeper Levels of Face-to-face Interaction.” Language \& Communication 5.2: 111-131. https://doi.org/10.1016/0271-5309(85)90004-7

Reber, Elisabeth. 2012. Affectivity in Interaction. Amsterdam/Philadelphia: John Benjamins. https://doi.org/10.1075/pbns.215

Reetz, Henning, and Allard Jongman. 2009. Phonetics. Malden, MA: Wiley-Blackwell.

Roggia, Aaron B. 2012. Eh as a Polyfunctional Discourse Marker in Dominican Spanish. Journal of Pragmatics 44: 1783-1798. https://doi.org/10.1016/j.pragma.2012.08.010

Schiffrin, Deborah. 1987. Discourse Markers. Cambridge: Cambridge University Press. https://doi.org/10.1017/CBO9780511611841

Schourup, Lawrence. 1982. Common Discourse Particles in English Conversation. Ohio: Ohio State University.

Schwenter, Scott. 1996. Some Reflections on O Sea: A Discourse Marker in Spanish. Journal of Pragmatics 25: 855-874. https://doi.org/10.1016/0378-2166(95)00023-2

Tagliamonte, Sali. 2005. "So Who? Like How? Just What? Discourse Markers in the Conversations of Young Canadians." Journal of Pragmatics 37: 1896-1915.

https://doi.org/10.1016/j.pragma.2005.02.017

Torres, Lourdes. 2002. "Bilingual Discourse Markers in Puerto Rican Spanish." Language in Society 31: 65-83. https://doi.org/10.1017/So047404502001033 
Torres, Lourdes, and Kim Potowski. 2008. “A Comparative Study of Bilingual Discourse Markers in Chicago Mexican, Puerto Rican, and MexiRican Spanish.” International Journal of Bilingualism 12: 263-279. https://doi.org/10.1177/1367006908098571

Travis, Catherine E. 2005. Discourse Markers in Columbian Spanish. Berlin: Mouton de Gruyter.

Ward, Nigel. 2006. "Non-lexical Conversational Sounds in American English." Pragmatics and Cognition 14: 129-182. https://doi.org/10.1075/pc.14.1.08war

Wright, Melissa. 2005. "Studies of the Phonetics-interaction Interface: Clicks and Interactional Structures in English Conversation." Doctoral Dissertation, University of York, UK.

Wright, Melissa. 2007. "Clicks as Markers of New Sequences in English Conversation." In Proceedings of the 16th International Congress of Phonetic Sciences, Saarbrücken, Germany, ed. by Jürgen Trouvain and William John Berry, 1069-1072. Saarbrücken: Universitat des Saarlandes.

Wright, Melissa. 2011a. “On Clicks in English Talk-in-interaction.” Journal of the International Phonetic Association 41: 207-229. https://doi.org/10.1017/S0025100311000144

Wright, Melissa. 2011b. “The Phonetics-interaction Interface in the Initiation of Closings in Everyday English Telephone Calls." Journal of Pragmatics 43: 1080-1099. https://doi.org/10.1016/j.pragma.2010.09.004

Zilio, Giovanni M. 1986. "Expresiones extralingüísticas concomitantes con expresiones gestuales en el español de América." In Actas de los congresos de la Asociación Internacional de Hispanistas IX, 139-151.

\section{Address for correspondence}

\section{Derrin Pinto}

Department of Modern and Classical Languages

University of St. Thomas

2115 Summit Avenue

St. Paul, Minnesota 55105

USA

drpinto@stthomas.edu 


\section{Biographical notes}

Derrin Pinto (PhD, University of California at Davis) is currently Professor of Spanish Linguistics in the Department of Modern and Classical Languages at the University of St. Thomas in St. Paul, Minnesota. He has published studies involving different areas of pragmatics, discourse analysis and second language acquisition.

Donny A. Vigil (PhD, Purdue University) is an Assistant Professor of Spanish in the Department of Modern and Classical Languages at the University of St. Thomas, St. Paul, Minnesota. His research interests include Spanish clicks as discourse markers, Spanish phonetics and phonology, sociolinguistics, history of the Spanish language, language contact, language variation and change, and traditional New Mexico Spanish. 
